\title{
Perancangan Program Monitoring Sales (Monals) PT Artistika Berbasis Mobile
}

\author{
Anastasia Siwi ${ }^{\mathrm{a} 1}$, Syarif Hidayatulloh ${ }^{\mathrm{b} 2}$, Feri Prasetyo ${ }^{, \mathrm{c} 3}$, Nico Diaspalasara ${ }^{\mathrm{d} 4}$, Ahmad Sinnun ${ }^{\mathrm{e}}$ \\ al,b,3, Fakultas Teknik Dan Informatika Program Studi Sistem Informasi Akuntansi Universitas Bina Sarana Informatika; \\ Jalan Kramat Raya No 98 Senen Jakarta

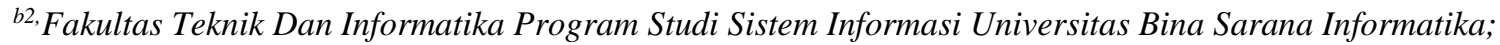 \\ Jalan Kramat Raya No 98 Senen Jakarta \\ ${ }^{4}$ Fakultas Teknik Dan nformatika Program Studi Sistem Informasi, Universitas Nusa Mandiri \\ Jl. Jatiwaringin No. 02, Cipinang Melayu, Jakarta Timur \\ ${ }^{e 5}$ Fakultas Teknik Dan Informatika Program Rekayasa Perangkat Lunak Universitas Bina Sarana Informatika; \\ Jalan Kramat Raya No 98 Senen Jakarta

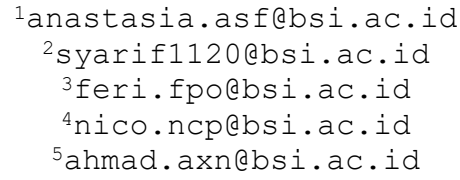

\section{Abstrak}

Salesman adalah orang yang melakukan pemasaran,penjualan,dan distribusi terhadap suatu produk kepada konsumen. Pengawasan kegiatan sales sangat lah penting bagi perusahaan, kecurangan data kegiatan dan penjualan masih sering terjadi yang mengakibatkan kerugian bagi perusahaan karena mulai dari rencana penjualan sampai realisasi rencana yang sudah dibuat sebelumnya semua masih dilakukan secara manual yang tidak praktis dan rawan kecurangan. Oleh Sebab itu dibuat sebuah program yang dapat membantu salesman melakukan pekerjaannya dan perusahaan dalam melakukan pengawasan. Aplikasi Mobile adalah salah satu solusi tepat selain mengikuti perkembangan jaman, penggunaan dan pemasangan nya pun terbilang sangat mudah begitupun bagi perusahaan pastilah sangat diuntungkan karena biaya oprasional nya pun sangat lah murah.Metode yang digunakan adalah prototype,pengamatan,studi pustaka dan menggunakan Bahasa pemrograman flutter(Mobile),PHP(Web Admin),HTML,CSS.

Kata kunci: Salesman,Pengawasan,Mobile,Sistem Informasi.

\section{Program Design Monitoring Sales (Monals) PT Artistika Mobile Based}

\begin{abstract}
A Salesman is a person who does marketing, sales, and distribution of a product to consumers. Supervision of sales activities is very important for the company, fraudulent activity data and sales still often occur which results in losses for the company because starting from the sales plan to the realization of the plans that have been made previously, everything is still done manually, which is impractical and prone to fraud. Therefore, a program was created that can help salesmen do their jobs and the company in carrying out supervision. Mobile application is one of the right solutions besides keeping up with the times, its use and installation is also very easy as well as for the company, it must be greatly benefited because the operational costs are very cheap. The methods used are prototype, observation, library research and using the flutter programming language. (Mobile),PHP(Web Admin),HTML,CSS.
\end{abstract}

Keywords: Salesman, Supervision,Mobile, Information Systems.

\section{PENDAHULUAN}

Salesman yaitu bagian dari suatu perusahaan yang kegiatannya adalah menjual, memastikan produk yang terlihat ataupun tidak. Selain itu juga berkewajiban untuk menawarkan aset atau produk sehingga bisa terjual dengan harga yang sesuai perencanaan perusahaan tapi juga diterima oleh konsumen.

Keberadaan Salesman sangat diperlukan dalam perusahaan dan merupakan ujung tombak suatu perusahaan, salesman biasanya akan menghadapi 
langsung konsumen alias one-on-one dengan pelanggan / outlet. Hal ini karena salesman bisa saja langsung datang ke lokasi calon konsumen atau pembeli, menghubungi lewat telepon, dan bisajuga bertemu di sebuah acara atau kegiatan.

Pengawasan kegiatan sales sangat lah penting bagi perusahaan , kecurangan data kegiatan dan penjualan masih sering terjadi yang mengakibatkan kerugian bagi perusahaan karena, mulai dari rencana penjualan sampai realisasi rencana yang sudah dibuat sebelumnya semua masih dilakukan secara manual yang tidak praktis dan rawan kecurangan [1]. Selain itu dalam hal manajemen dan pengolahan data masih belum terorganisir dengan baik dan kurang efisien terutama dalam hal penyampaian informasi [2]. Sering kali dari pihak atasan ataupun manager memiliki informasi ataupun data kegiatan dan penjualan yang tidak akurat dan up to date [3] Aplikasi mobile pada saat ini merupakan teknologi yang sangat berkembang pesat [4]. Perkembangan aplikasi mobile yang pesat berdampak pada gaya hidup masyarakat sehari-hari. Aplikasi mobile saat ini banyak digunakan untuk membantu aktivitas pada kehidupan sehari-hari [5]. Keunggulan dari aplikasi mobile adalah sifatnya yang mudah [6]dan dapat digunakan dimana saja sehingga aplikasi ini sangat cocok untuk membantu aktivitas-aktivitas yang memiliki mobilitas tinggi [6] .

PT Artistika Merupakan Perusahan Nasional yang bergerak dalam bidang Produksi pembuatan keramik tegel untuk lantai dan lubang udara, di mana untuk melancarkan produksinya di butuhkan tenaga marketing untuk memasarkan produknya dalam hal ini adalah sales, Sehingga butuh sebuah inovasi aplikasi [7] yang dapat menunjang kinerja dari tugas sales. Pelaksanaan penelitian ini menggunakan metode prototype. Tahapan penelitian "Program aplikasi Monsals (monitoring sales) berbasis Android". Dimulai dengan melakukan analisa dan pengumpulan data kebutuhan sistem mengenai transaksi pada optikal, guna memberikan gambaran secara garis besar sistem yang akan dirancang. Android merupakan Sistem operasi yang sedang berkembang saat ini [8]

Berdasarkan uraian diatas maka dilakukan penelitian tentang "Program aplikasi Monsals (monitoring sales) berbasis Android." Yang nanti perkembangannya akan di terapkan pada PT Artistika dan Prosenya dapat memudahkan proses penjualan [9], monitoring kegiatan [10]., pelayanan dan pengelolaan data dan laporan pada sales

Dengan memudahkan kegiatan tersebut dapat banyak memperoleh keunggulan [11] dalam pencapaian kerja, sehingga hasil pun meningkat [8] dan maksimal demikian juga laporan dapat terpantau dengan baik[12]

\section{METODE PENELITIAN}

Pada kegiatan penelitian ini mengunakan alur metode sebagai berikut:

a. Studi Literatur, dimulai dengan mencari dan merangkum kepustakaan apa saja yang dapat menunjang pengerjaan Penelitian ini[13].

b. Pengumpulan Data, dilakukan dengan mengumpulkan data alur pada kegiatan sales. Data alur ini digunakan sebagai bahan untuk merancang sistem aplikasi Monsals (monitoring sales) berbasis Android.

c. Pemodelan Sistem, dengan merancang sistem informasi untuk Monsals (monitoring sales) berbasis Android. Tahap ini juga merancang alurdari sistem yang dibuat.

d. Implementasi, penerapan sistem informasi Monsals (monitoring sales) berbasis Android.

e. Testing dan Analisis, setelah dilakukan implementasi, tahap selanjutnya adalah testing.

f. Penyusunan Laporan, dokumentasi dan pelaporan hasil pengerjaan Tugas Akhir sesuai kaidah dan sistematika yang telah ditetapkan.

\section{HASIL DAN PEMBAHASAN}

A. Analisis kebutuhan

Hal yang perlu dipahami dalam tahap analisa suatu perancangan progam ini diantaranya ialah aplikasi ini dirancang agar dapat digunakan dengan mudah dan efisien [14] oleh sales karena demi meningkatkan pendapatan sales dan meningkatkan keuntungan perusahaan [15]. Perancangan program monsals(Monitoring Sales) ini menggunakan 2 device dan 2 antarmuka diantaranya adalah sebagai berikut :

1) Analisa Kebutuhan Sales (Mobile)

- Sales dapat melakukan login

- Sales dapat melakukan realisasi pada rencana kunjungan

- Sales dapat mencatat penjualan pada saat kunjungan

2) Analisa Kebutuhan Pimda/Admin (Web)

- Admin dapat melakukan login

- Admin dapat menambah,mengubah dan menghapus data sales.

- Admin dapat menambah,mengubah dan menghapus data produk

- Admin dapat menambah,mengubah dan menghapus data kategori produk.

- Admin dapat menambah,mengubah dan menghapus data customer.

- Admin dapat menambah,mengubah dan menghapus data rencana kunjungan.

- Admin dapat menambah,mengubah dan menghapus data kategori rencana

- Admin dapat menambah,mengubah dan menghapus data cabang 
- Admin dapat melihat dan print laporan kunjungan sales

- Admin dapat melihat dan print laporan penjualan sales

B. Entity Relationship Diagram (ERD)

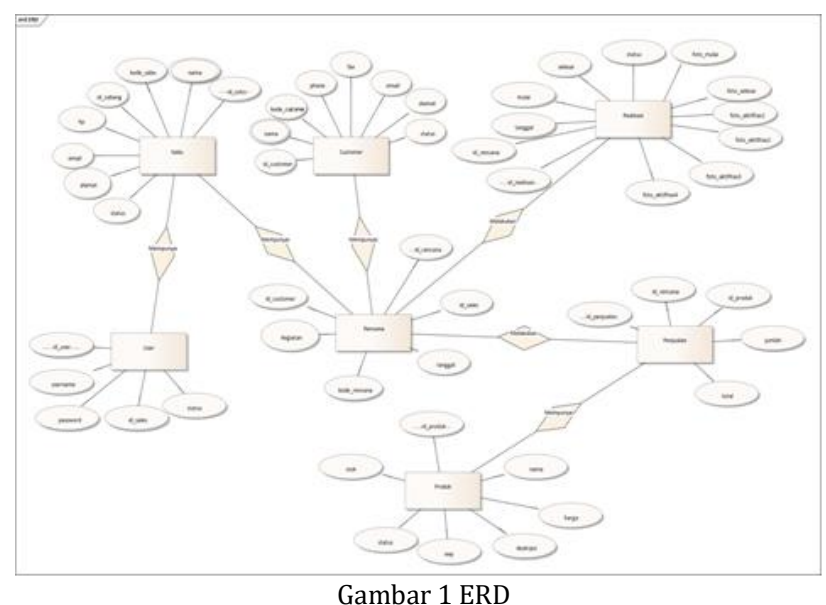

C. Logical record Struktur

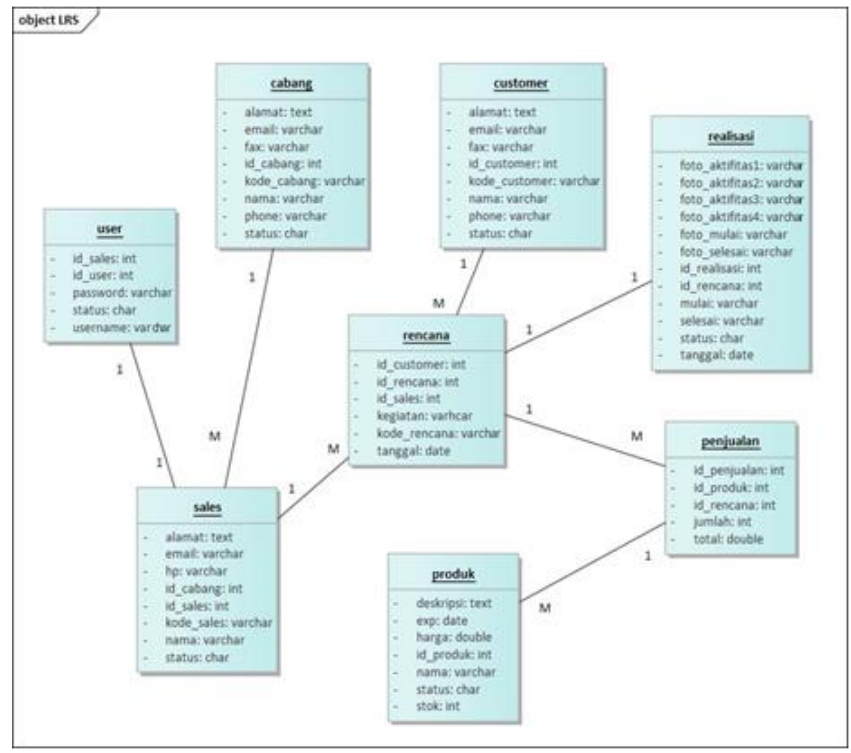

Gambar 2 LRS

\subsection{Spesifikasi program}

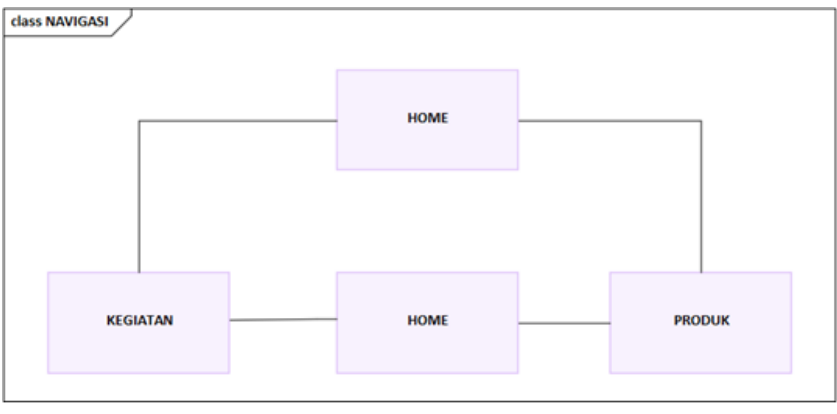

Gambar 3. Navigasi Persedian

Digunakan untuk memonitoring persetian yang ada di PT artistika sehingga admin dapat menginformasikan kepada sales yang dapat berelasi dengan aplikasi sales.

\section{Navigasi admin web}

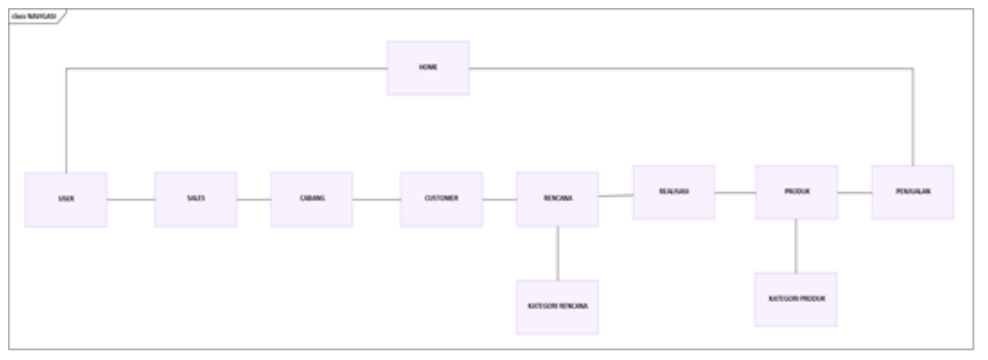

Gambar 5 Navigasi admin

Navigasi ini diharapkan admin dalam melakukan kegiatanya untuk memonitoring kebutuhan sales dengan web.

\section{F. Implementasi}

Implementasi rancangan antar muka pada aplikasi monsels (mobile) digunakan oleh sales berdasarkan hasilrancangan antar muka .

1) Spalsh Screen

Proses yang pertama kali ketika membuka aplikasi mobile aplikasi Monsals halaman yang pertama kali muncul yaitu Splash Screen. 


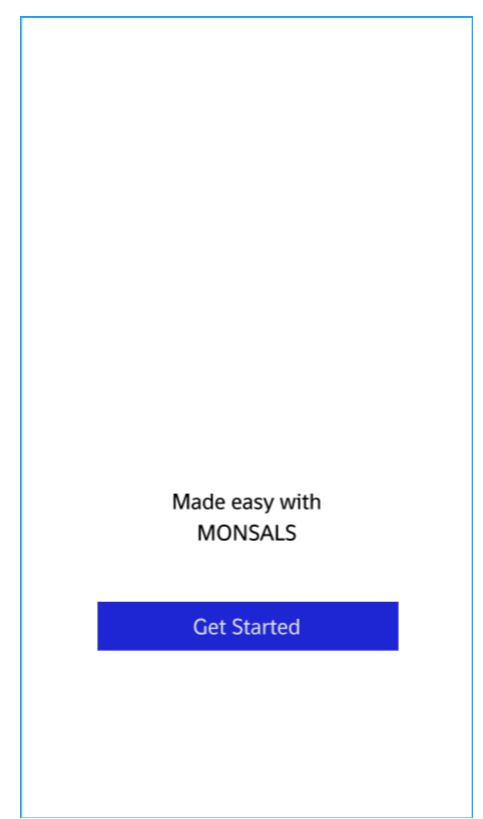

Gambar 6 Splash Screen

\section{2) Halaman Login}

Sales harus melakukan login terlebih dahulu untuk dapat menggunakan aplikasi Monsals Jika login berhasil,maka sales akan masuk kehalaman Utama.

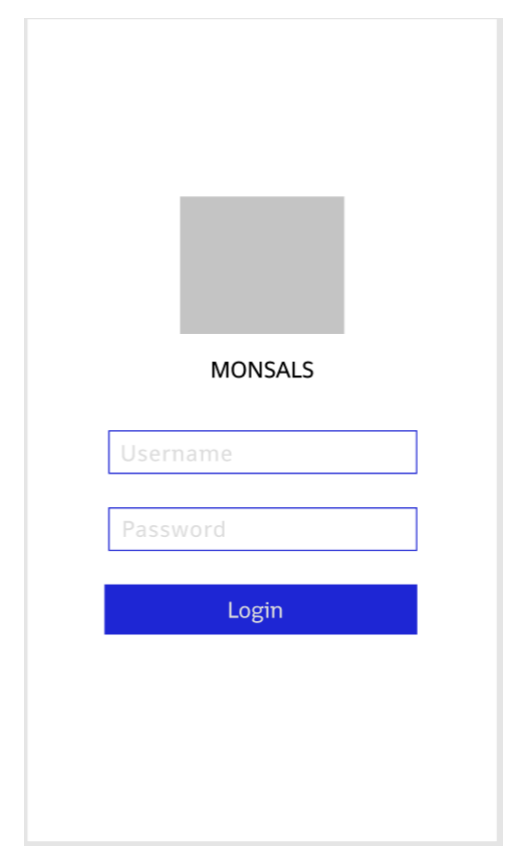

Gambar 7 Halaman Login

\section{3) Halaman Utama}

Setelah Sales login aplikasi Monsals akan menampilkan halaman Utama Halaman utama berisi detail data Sales yang login selain itu di halaman Utama juga menampilkan data rencana,realisasi,persentase rencana yang sudah di kerjakan dan hasil penjualan per rupiah berdasarkan filter bulan dan tahun.

\section{MONSALS | 27/03/2021 08:30:54}
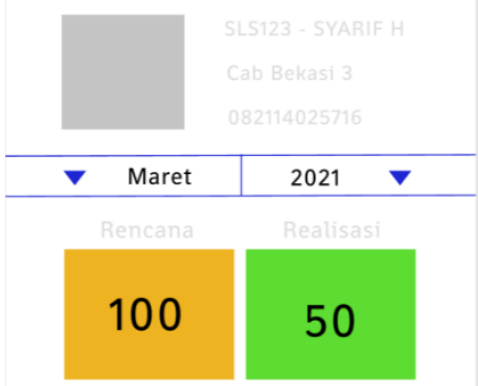

$50 \%$

RP .10 .000 .000

Kegiatan Home Produk

Gambar 8 Halaman Utama

\section{4) Halaman Kegiatan/Rencana}

Setelah memilih/mengklik navigasi kegiatan, sales akan di arahkan ke halaman kegiatan, dihalaman ini berisi daftar kegiatan/rencana berdasarkan filter bulan dan tahun.

\section{MONSALS | 27/03/2021 08:30:54}

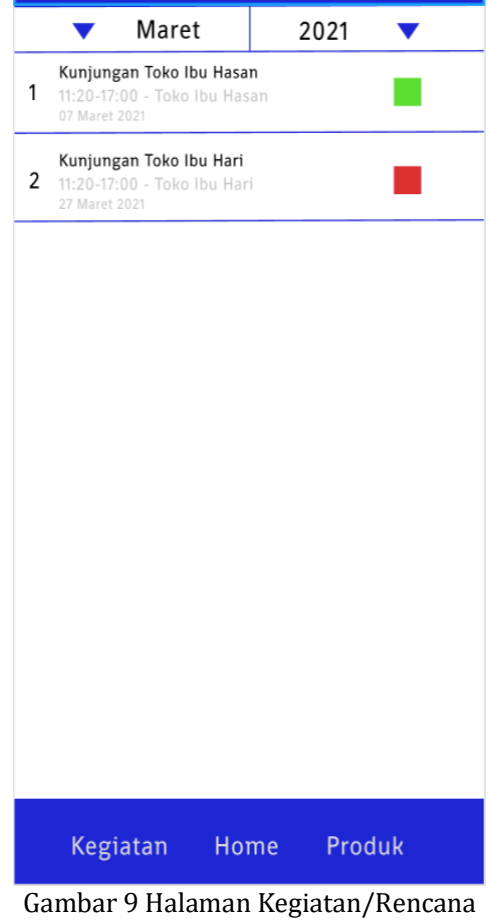




\section{5) Halaman Form Realisasi}

Setelah memilih salah satu rencana/kegiatan, sales akan di arahkan ke halaman form realisasi, dihalaman ini sales harus mengisi form yang tersedia .

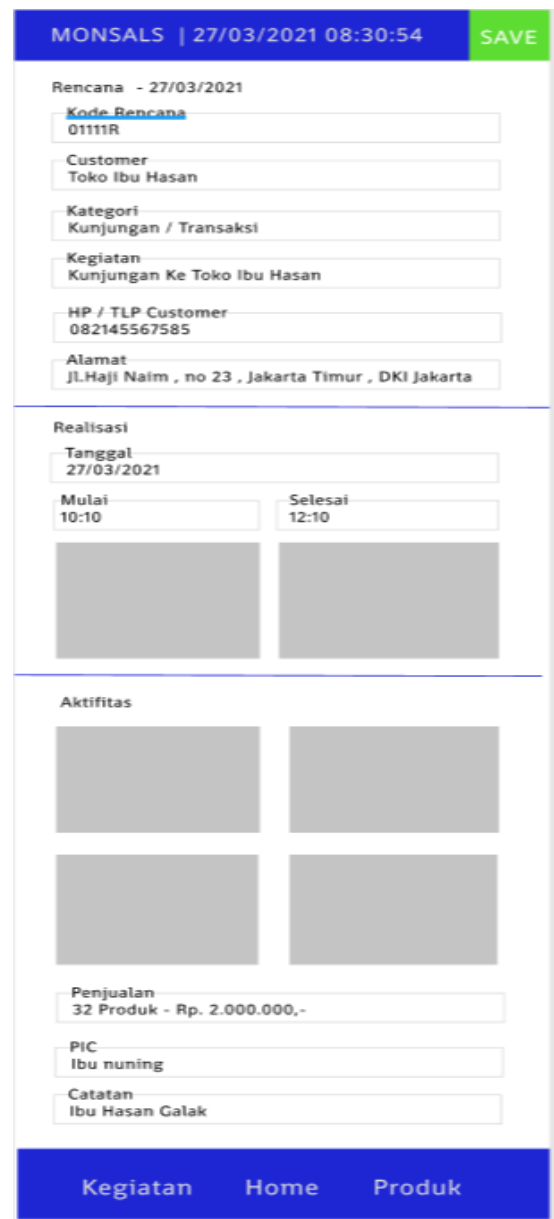

Gambar 10 Halaman Form Realisasi

\section{6) Halaman Penjualan}

Ketika klik Input text penjualan sales akan diarah kan ke halaman penjualan ,dihalaman ini sales akan memasukan transaksi penjualan pada rencana yang telah dipilih .
MONSALS | 27/03/2021 08:30:54 BACK

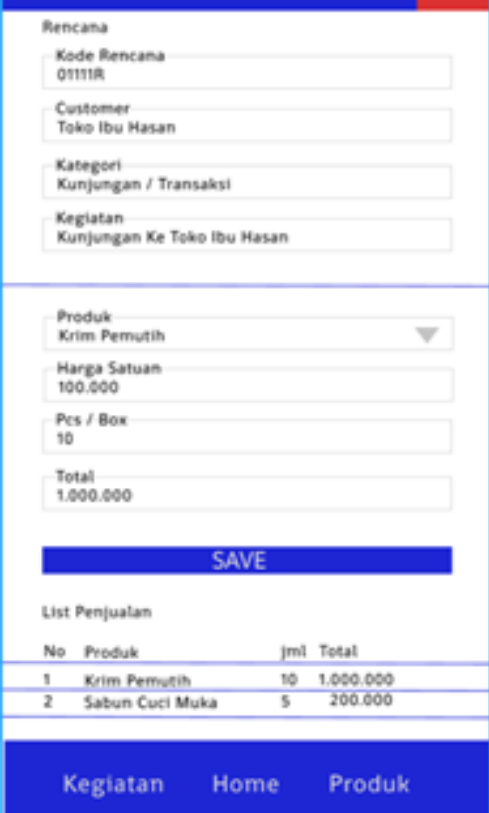

Gambar 11 Halaman Penjualan

\section{7) Halaman Produk}

Setelah memilih / mengklik navigasi produk, sales akan di arahkan ke halaman produk, dihalaman ini berisi daftar produk berdasarkan filter kategori.

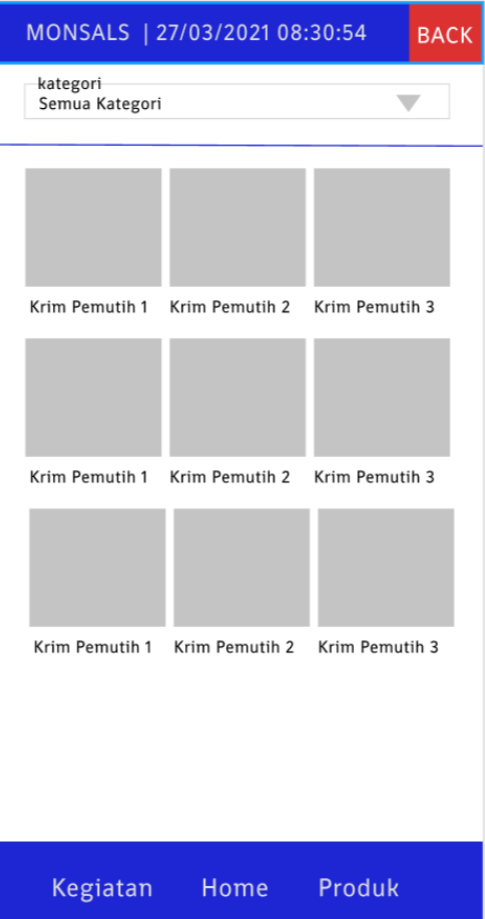

Gambar 12 Halaman Produk 


\section{8) Halaman Detail Produk}

Ketika memilih/klik salah satu produk, sales akan di arahkan ke halaman detail produk, dihalaman ini berisi penjelasan produk secara detail.

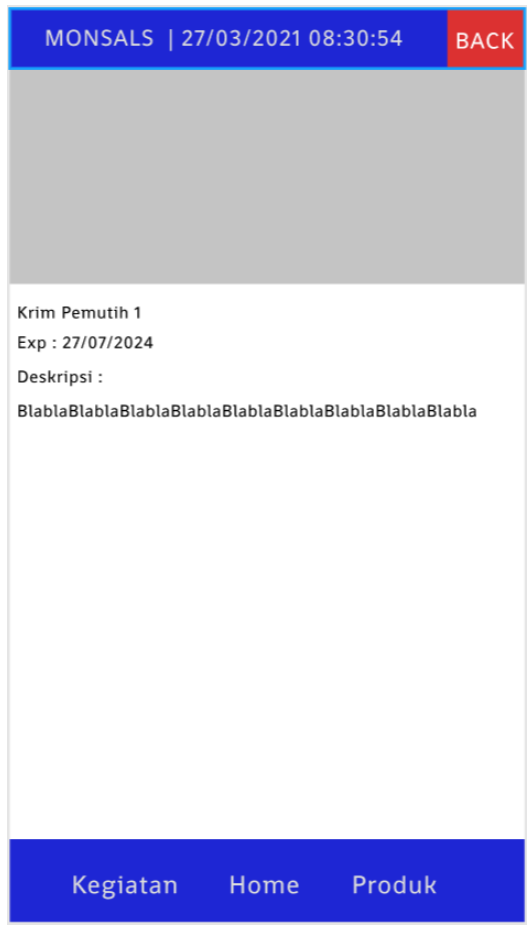

Gambar 13 Detail produk

\section{9) Halaman Dashboard / Halaman Utama}

Setelah Login admin/atasan akan di arahkan ke halaman dashboard,dihalaman dashboard ini berisi jumlah data user, sales, cabang, customer, total rencana,realisasi,penjualan dan presentase dari rencana/penjualan berdasarkan filter bulan dan tahun saat ini .

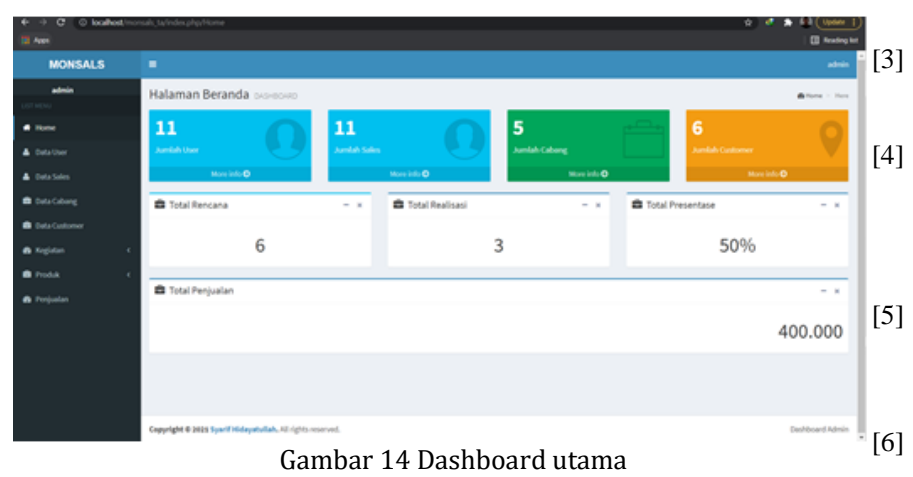

\section{0) Halaman Penjualan}

Ketika memilih /klik navigasi penjualan ,admin akan di arahkan ke halaman detail penjualan yang berisi data penjualan, dihamalan ini admin dapat melihat dan cetak penjualan berdasarkan filter bulan dan tahun

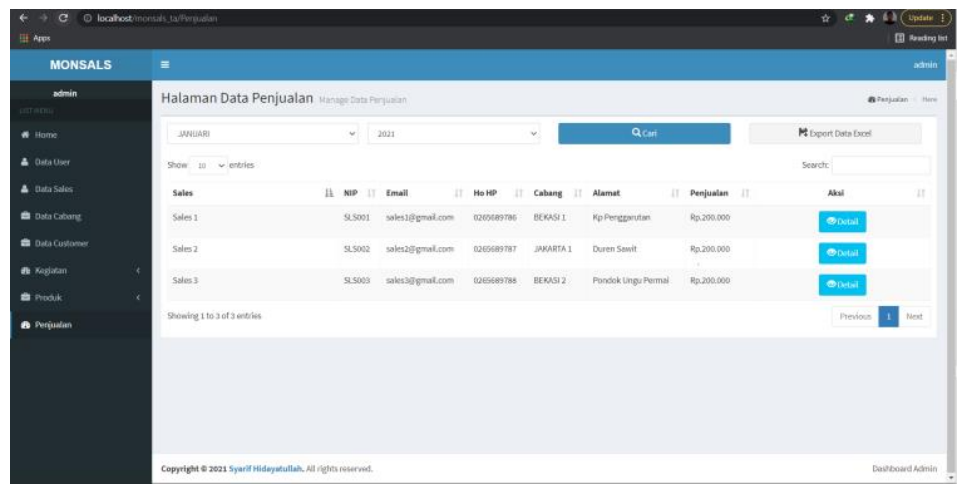

Gambar 12

Data Penjualan

\section{KESIMPULAN}

Dengan adanya aplikasi Monsals ini agar dapat memberikan kemudahan kepada pengguna terutama untuk PT Artistika Dalam Memotnitoring Sales agar mudah menngawasi aktifitas pegawai/sales dalam melaksanakan penjualan produknya ke konsumen. Dengan adanya fasilitas admin berbasis web pemilik usaha/atasan dalam hal ini PT Artistika juga dapat mengelola data dan meminimalisir terjadinya kehilangan data, Dengan adanya fasilitas admin berbasis web ini juga pemilikusaha/atasan juga dapat dapat melihat laporan kegiatan dan penjualan secara realtime bahkan laporan-laporan harian dan bulanan dapat dengan mudah diprint ataupun hanya melihatnya agar dapat mengurangi penggunaan kertas

\section{DAFTAR PUSTAKA}

[1] Fridayanthie W E, 2015 Perancangan Sistem Informasi Penjualan Peralatan Hiking Berbasis Desktop Pada Toko Cimone Outdoor Tangerang J. Khatulistiwa Inform. 3, 2 p. $143-151$.

[2] Handayani S, 2018 Perancangan Sistem Informasi Penjualan Berbasis E-Commerce Studi Kasus Toko Kun Jakarta J. Ilm. Vol. 10, 2 p. 182.

Lesmono I D and Romadoni F, 2018 Sistem Informasi Penjualan Merchandise Berbasis Web Pada PT Come Indonusa Dengan Metode Waterfall J. Evolusi 6, 2 p. 91-97.

Yoraeni A, 2017 EREFERENSI PENGGUNA ANDROID TERHADAP PENDUKUNG KEPUTUSAN MEMILIH FITUR SMARTPHONE DIKALANGAN MAHASISWA AMIK BSI BEKASI J. Inov. Inform. 2, sistem informasi p. $48-53$.

Efendi, Rusdi, Purwandari, Putri, Endina, Aziz, Abdul M, 2015 Aplikasi Pengenalan Huruf Hijaiyah Berbasis Marker Augmented Reality Pada Platform Android pseudocode 2 , komputer p. 124-134.

Sarbini, Nurtantyo, Riska, Efytra, Dian, Yuliana, Ariie WK D, 2018 Rancang Bangun Sistem Informasi Akademik Berbasis Android Dedikasi 15, Komputer p. 122-125.

[7] Leo Aldianto, Leo Aldianto, Isti Raafaldini Mirzanti, Dedy Sushandoyo E F D, 2018 Pengembangan Science Dan Technopark Dalam Menghadapi Era Industri 4.0 - Sebuah Studi Pustaka J. Manaj. Indones. 18 p. 68-76.

[8] Haqi Bay S S H, 2019 Aplikasi Absensi Dosen dengan Java dan Smartphone sebagai Barcode Reader Jakarta: PT Elex Media Komputindo.

[9] Hidayatun N Herlawati H and Frieyadie F, 2013 Aplikasi Web Untuk Sistem Informasi Akademik Sma Negeri 33 Jakarta $J$. Pilar Nusa Mandiri 2, 9 p. 174-183. 
[10] Pradiska, Nanang, Laksono , Widyo P, 2017 Analisis ConjointPemilihan Smartphone pada MahasiswaTeknik Industri UNS in Seminar dan Konferensi Nasional IDEC 2017 p. $306-310$

[11] Jogiyanto H, 2005 Analisa dan Design Sistem Informasi " Pendekatan Terstruktur Teori dan Aplikasi Bisnis Andi Offset.

[12] Mulyati D, 2012 Analisis efektivitas peralatan produksi pada pt. bahari dwikencana lestari kabupaten aceh tamiang.

[13] Hidayat M K and Ningrum R C P, 2017 Sistem Informasi Penjualan Online Pada Toko Yusuf Bekasi J. Comput. Inf. Technol. Vol.2 No.2 p. 24-30.

[14] Pratiwi H, 2016 Buku Ajar Sistem Pendukung Keputusan .

[15] Wartaka Mohamad, 2004 Analisa Preferensi Konsumen Produk Lipstik dan Kaitannya dengan Segmentasi Produk. 